\title{
L'ocàs de la vida religiosa a Borriana
}

\author{
Guillem Ríos I CANós (guillemrios22@gmail.com)
}

Diuen que un final és només un principi. Tal vegada ens trobem a l'inici d'una nova etapa, però del que no hi ha dubte és que assistim al final de la Borriana sorgida a finals del segle XIX.

Vivim i patim la decadència de la citricultura; però eixa lenta expiació de l'activitat que tot ho amerava, ve guarnida amb altres canvis en el nostre paisatge quotidià, en el qual, per exemple, era palesa la presència dels ordes religiosos que ens van acompanyar durant el segle $\mathrm{xx}$.

A la nostra pròpia intrahistòria s'unix un canvi d'època en l'Església catòlica, amb una evident falta de vocacions religioses. En el seu tradicional missatge de Nadal a la cúria romana, el papa Francesc assenyalava: «Estem vivint un canvi d'època. Hui no som els únics que prodü̈m cultura, ni els primers, ni els més escoltats».

Dos-cents quaranta-dos anys van estar els mercedaris entre nosaltres; concretament, entre 1564 i 1836, coincidint amb la desamortització de Juan Álvarez Mendizábal, que va desposseir els ordes religiosos de tot el seu patrimoni. El colp definitiu als ordes regulars va arribar el 29 de juliol de 1937. Un reial decret del govern presidit per José María Calatrava va extingir a la península, illes adjacents i possessions espanyoles a l'Àfrica, tots els monestirs, convents, collegis, congregacions, i la resta de cases de religiosos d'ambdós sexes, excepte algunes excepcions vinculades a collegis de missioners d'ultramar. Les implicacions i conseqüències polítiques d'estes mesures contra els religiosos són del tot conegudes, ja que van entrar a formar part dels reiterats conflictes i intransigències entre espanyols.

A partir de la Restauració borbònica, fonamentada en la Constitució de 1876, es va produir un clima polític més favorable a la fundació de nous ordes religiosos i la restauració dels antics, i alguns monestirs van poder reviscolar la vida monacal. Va ser a finals del segle XIX quan es va produir una eclosió de nous convents gràcies al suport econòmic de les classes benestants - conservadors i tradicionalistes - situats en les antípodes dels moviments anticlericals que van renàixer en les primeres dècades del segle xx.

En els anys pròxims a 1890 Borriana era una població de 7.900 habitants i 1.250 edificis. Segons descriu Bernardo Mundina en 1873: «les seues cases són majoritàriament de pis baix, però les del centre són de construcció moderna i elegant, amb bones estances, luxoses habitacions i de molt bona planta. Els seus carrers són propis de població antiga, estrets $i$ torts, a pesar d'haver-se millorat molt els del centre amb l'eixample i alineació dels edificis moderns».

La nostra ciutat, des de l'arribada dels primers vapors anglesos cap al 1870, era una ciutat en plena efervescència. Les seues taronges viatjaven per tota Europa. Les seues gents es veien afavorides per la prosperitat tarongera, $i$ una xicoteta burgesia es refermava gràcies a un esponerós comerç internacional.

Part d'eixa xicoteta burgesia adinerada va ser la que va determinar que havia arribat el moment de col-laborar en la magnificència dels cultes religiosos. I així va ser com es 
va escometre en estos anys l'ampliació de l'església del Salvador, prolongant la seua nau en dos trams perquè tota l'església quedara connectada amb la capella de la Comunió.

El 22 d'agost de 1882 es va col-locar la primera pedra de la nova ermita de Sant Blai. També estava edificant-se la nova parròquia de Santa Bàrbara, obra de l'arquitecte Godofredo Ros de Ursinos, inaugurada al culte en 1891.

Quasi coincidixen en la seua arribada a Borriana bona part dels ordes i congregacions religiosos. Les Germanes de Nostra Senyora de la Consolació el 6 de gener de 1886. Les Monges Dominiques el 16 de juliol de 1890. Els Carmelites descalços en 1896. O les Serventes de Jesús de la Caritat en 1899.

Va ser una eclosió d'esperit catòlic. I va ser en aquella Borriana on s'establiren dos grans monestirs: el de les Monges Dominiques i el dels Carmelites Descalços; dos ordes que acaben d'anunciar recentment el seu comiat.

A partir d'ara s'obri un futur incert pel que fa a les edificacions. Tots recordem l'estat de l'exconvent de la Mercè quan no tenia un ús específic. El seu deteriorament era notable, fins al punt de desfavorir tot el barri. En el cas de les esglésies se suposa que se'n farà càrrec el Bisbat; la part buida del convent dels Frares intuïm que podria ocupar-la el col-legi Illes Columbretes, però no sabem res del futur del convent de les Monges Dominiques.

Cal recordar que les primeres a anar-se'n a mitjans dels anys noranta van ser les Serventes de Jesús, instal-lades en la Carrera, que s'ocupaven de cuidar els malalts durant les nits acudint a les cases on les necessitaven. Van ser reemplaçades per les monges Reparadores de la Immaculada Concepció, que se'n van anar definitivament en 2017.

Les mares de la Consolació, que originàriament atenien l'antic Hospital de Sant Blai des del segle XIX, romanen al capdavant del col-legi, però en l'any 2007 van deixar de fer-se càrrec de la Residència de Càritas, que dirigien des de 1965.

\section{Monestir de la Sagrada Família de les monges dominiques}

Cent trenta anys de contemplació. És el temps transcorregut des del 16 de juliol de 1890. Una data assenyalada, perquè rere segles d'història, havia entrat a Borriana la primera comunitat religiosa contemplativa.

Des de 1890, els murs del monestir han guardat zelosament la vida d'oració, silenci i treball d'una comunitat de monges dominiques en ple cor de Borriana.

Se sap que el dominic valencià sant Vicent Ferrer va predicar a Borriana en 1412 durant un viatge de Barcelona a València. I no seria gens estrany que també ho haguera fet, encara que no en tenim constància, en 1410, de pas cap a València, provinent de Morella.

També un altre gran sant dominic i valencià va estar a Borriana. Va ser sant Lluís Bertran qui, a petició dels jurats de la nostra ciutat, va arribar a la població en la Quaresma de 1574 per a fer la predicació completa durant els quaranta-sis dies.

En la parròquia del Salvador hi ha una capella dedicada a sant Vicent Ferrer de la qual ja es té notícia en 1716, la qual cosa vol dir que pot datar de molt abans. Actualment, la capella està presidida per una talla de sant Vicent de l'artista tortosí Àngel Acosta.

Igual que succeïx amb els carrers dedicats a mercedaris en l'entorn de l'exconvent de la Mercè, també trobem unes quantes travessies que recorden els vincles de Borriana amb l'orde dels dominics. 
En primer lloc destaca el carrer de Sant Vicent, un dels primers que es van edificar quan es va començar a construir fora del perímetre de les muralles. Es diu que sant Vicent va predicar des de la torre baluard del portal de València, just a l'inici del carrer que porta el seu nom.

Connectat amb el carrer de Sant Vicent, trobem el carrer del Roser (rosari), del qual són grans devots els dominics.

En un dels primers eixamples de la ciutat, quan esta creixia cap al nord-oest, va nàixer el carrer de Santa Rosa de Lima, primera santa d'Amèrica, dominica santificada a l'ombra del convent de Santo Domingo de Lima.

Travessant el carrer de Santa Rosa, en la prolongació del carrer de la Mare de Déu de la Saleta, està el carrer de Sant Doménec de Guzmán, fundador de l'orde de Predicadors.

Uns dels carrers de l'eixample del sud, al barri de la Bosca, es va dedicar a sant Martí de Porres, fruit de l'entranyable devoció que la ciutat professa al sant mulat dominic.

En els canvis en la nomenclatura dels carrers de la ciutat, en la dècada dels huitanta del segle passat, la plaça on s'ubica el monestir va rebre el nom de placeta de les Monges, com popularment se l'ha identificada. Un senzill homenatge a les monges de clausura.

\section{ELS FUNDADORS}

Dos il·lustres borrianencs: mossén José Ramón Monserrat Llopis i mossén Juan Bautista Llopis Montoya, sacerdots, cosins, i descendents de famílies acomodades de Borriana, van prendre la decisió de crear un convent religiós a la seua vila natal.

Mossén José Ramón Monserrat va nàixer a Borriana en 1851, i sembla que va voler ser dominic, però la seua vocació sacerdotal va quallar en el seminari diocesà de Tortosa.

El pare Monserrat va tindre un paper molt destacat d'atenció als malalts durant el còlera de 1885 . Els veïns més adinerats van fugir de la ciutat, i els metges i alguns sacerdots, com el pare Monserrat, van fer front a la greu situació. En tres mesos hi van morir 250 persones (124 homes i 126 dones) a causa de l'epidèmia.

El 15 de juny de 1885 el municipi es va veure obligat a establir en l'edifici anomenat la Beneficència, propietat de l'aleshores alcalde, Benjamín González Monsonís, situat en ple camp -en el que hui és el cantó del carrer de la Virgen de la Cabeza i la ronda de Pere IV - un llatzeret amb destinació als colèrics. Allí va estar el pare Monserrat dia i nit, fins que el 6 de setembre del mateix any 1885 l'Ajuntament va acordar declarar Borriana lliure de l'epidèmia, motiu pel qual es va cantar un Te Deum en la parròquia i es van organitzar celebracions d'acció de gràcies.

Un any després d'aquella epidèmia va començar a prendre cos en mossén Monserrat la idea d'una fundació religiosa a Borriana. El seu gran desig era el d'un convent de religiosos dominics, gràcies a les exhortacions de la seua família, com la seua cosina germana, sor María Teresa Felis Llopis, que pertanyia al monestir de monges dominiques de Vila-real. No va poder ser un convent de frares dominics, i tots els tràmits es van resoldre amb facilitat i rapidesa quan la seua idea fundacional va canviar cap a un monestir de monges dominiques. No conforme amb això, una vegada realitzada la fundació, i ja erigida la nova comunitat, mossén José Ramón va ser el capellà de les 
monges, es va fer terciari dominic, i va continuar sent el benefactor de la comunitat fins a la seua mort en 1915, als 65 anys.

En el setmanari liberal La Unión del 28 d'agost de 1915 s'informava:

«El 19 del corriente falleció en esta ciudad el venerable Sacerdote D. José Ramón Monserrat Llopis, a los 65 años de edad (que en paz descanse). La noticia de su muerte ha causado viva emoción en nuestra ciudad, por las muchas simpatías que gozaba entre sus paisanos el popular Mosen Chosep. Sus trabajos apostólicos, su gran celo por el cumplimiento de su deber, quizás hayan acelerado la muerte del infatigable Mosen Monserrat. Durante los años de su ministerio sacerdotal, ha ejercido importantes cargos en la Diócesis de Tortosa. Empezó su carrera sacerdotal con el nombramiento de Coadjutor de Tirig; luego, y por los años, Coadjutor de esta parroquia, Cura Ecónomo de Almazora, Vicario de las Dominicas y, últimamente Beneficiado de esta Iglesia. Por muchos años fue misionero de la Diócesis, recorriendo en sus misiones casi todos los pueblos del Maestrazgo. Burriana jamás podrá olvidar los incesantes trabajos de Mosen Monserrat durante el cólera del 85, en cuyos días se le vio continuamente asistiendo a los contagiados de aquella peste. En compañía del Doctor D. Juan Bautista Llopis, cooperó en gran manera a la fundación del Convento de Dominicas de nuestra Ciudad. En el acto del entierro, que tuvo lugar el 20 por la tarde, se pusieron de manifiesto las simpatías de que gozaba el finado. El jueves de esta semana se han celebrado los funerales y en dicho día se reiteraron las muestras de veneración y respeto a tanmeritísimo Sacerdote. A su afligida familia, y de un modo especial a su hermana Luisa, les mandamos nuestro más profundo pésame».

Sis anys més tard, el 18 d'octubre de 1921, les seues despulles van ser traslladades a l'església del monestir de les dominiques.

José Ramón Monserrat Llopis (que posseïx com a homenatge una placa en sa casa natalícia del carrer del Forner de Tichell) era besnet del doctor en Farmàcia, Francisco Mayner, en la finca del qual es va trobar una imatge d'un eccehomo. El divendres 12 d'octubre de 1787, un dels bracers que cavaven en l'heretat de l'apotecari Francisco Mayner Llorens de San Esteban, en la partida del Rovellat, va trobar, colgada en un camp, una imatge d'un eccehomo llaurada sobre pedra. Mayner la va col-locar en l'alqueria de la seua heretat. A la vista de l'afluència de devots a l'alqueria per a visitar la imatge, Mayner va sol-licitar alçar una ermita, l'actual ermita de l'Eccehomo, que va ser beneïda el 15 de setembre de 1795.

L'altre fundador va ser mossén Juan Bautista Llopis Montoya, sacerdot que va destacar per la seua intel-ligència. Va ser beneficiat de la col-legiata de Sant Bartomeu de València. Doctor en Teologia. Advocat del Tribunal del Regne de Madrid. Va respondre sol-lícit a la primera crida del seu cosí per a posar en marxa la idea de la fundació a Borriana. Tenia 35 anys, els mateixos que mossén José Ramón, quan va començar la tramitació de la nova fundació. Va morir a Madrid en 1892, als 40 anys, dos anys després d'haver vist consolidada la fundació del monestir de les dominiques. En 1906 les seues restes mortals van ser traslladades des del cementeri de San Lorenzo de Madrid a l'església del monestir de Borriana. Allí van estar fins a l'estiu de 1936, quan les seues despulles i les de mossén Monserrat van ser portades a la fossa comuna situada en la part posterior del cementeri. 


\section{LA FUNDACIÓ}

Com hem assenyalat, la primera idea de José Ramón Monserrat era la de fundar a Borriana un convent de dominics. Va escriure al pare provincial dels dominics a Espanya i la contestació degué ser clara: era impossible pensar en un nou convent quan en aquells moments s'estava treballant amb esforç per a restaurar els dos grans centres dominics de Barcelona i de València, seriosament danyats després de les guerres del segle XIX.

Ja en estos primers passos va tindre molt a veure mossén Juan Bautista Llopis, que per la seua residència a Madrid i pel seu càrrec tenia fàcil accés a les autoritats religioses.

Cap dels dos sacerdots es va desanimar davant la negativa, i immediatament van reprendre la senda. Ja que no podia ser un convent de frares, mantindrien l'orde de Predicadors, però ara en la seua branca femenina. Fundarien a Borriana un monestir de monges dominiques de clausura.

Un monestir de clausura, encara que siga per a una comunitat reduïda, ha de ser necessàriament un edifici gran, ja que les monges han de desenvolupar en el recinte tota la seua vida. Havia de comptar amb celles suficients per a cadascuna de les religioses i amb sales comunes, com ara: església amb un cor ampli, sala capitular, menjador, cuina, rebost, biblioteca, sala de costura, llavador, magatzem, locutori, cementeri i una horteta. També, seguint l'edificació tradicional dels monestirs, les estances havien d'estar distribuïdes al voltant d'un claustre amb arcs, centrat per un pou.

Tot açò necessitava un solar extens. I per descomptat faltava el més important, les monges que l'havien d'habitar.

No és estrany que el primer pas fora posar-se en contacte amb les monges dominiques de Vila-real, monestir que passava en aquells anys per moments d'auge i esplendor vocacional. La petició a les monges per a fundar un monestir en la veïna Borriana degué causar entusiasme, ja que immediatament van donar permís perquè un grup de religioses, entre les quals hi havia dues borrianenques: sor Teresa Felis Llopis (cosina germana del pare Monserrat) i sor Elena Montoro Palomar, isqueren del seu convent per a fundar el nou monestir.

El segon punt important es va posar en marxa immediatament. Es va buscar un solar i es va localitzar al final del Raval, on els tarongers acariciaven la ciutat, on arrancava el camí cap a València. Allí hi havia un terreny ampli en què folgadament es podia construir el monestir i l'església. La finca era propietat de la senyora Elvira González, a qui li la va adquirir el pare Juan Bautista Llopis Montoya a través d'escriptura de compravenda firmada el 2 de setembre de 1887.

I allí, a principis de 1888 , es van iniciar les obres, que van durar dos anys i mig.

A principis de 1890 ja estava alçat tot el monestir, a excepció de l'església, que hauria d'esperar uns anys.

Va resultar un edifici sobri i auster, sense adorns de cap classe, amb murs de maçoneria amb molt poques obertures a l'exterior, atés el caràcter claustral a què es destinava. Tres plantes rodejaven el claustre, que s'obria sobre sis arcs de mig punt en cada llenç, igualment sense adorns, que s'alternen amb trams de parets mestres per a la sustentació de tot l'edifici.

$\mathrm{Al}$ mig del claustre es va poder formar un jardí que les mateixes monges han cuidat amb cura. Hui en dia encara es conserva una bonica olivera centenària, testimoni dels primers anys de vida monàstica. 
El 14 de juliol de 1890 els dos sacerdots fundadors, José Ramón Monserrat i Juan Bautista Llopis, es van traslladar al convent de Carcaixent per a arreplegar sor María Loreto Canut, que s'havia mostrat disposada a formar part de la nova fundació. Dos dies més tard van arribar al monestir del Corpus Christi de Vila-real, on se'ls van unir les cinc monges que n'eixirien: sor Carmen Leyva Ballester (nova priora); sor Teresa Felis Llopis, de Borriana; sor Elena Montoro Palomar, de Borriana; sor Encarnación Galve Osuna, d'Onda; i sor Rafaela Pérez López, de Castelló; i tots junts van emprendre viatge cap a Borriana. En el pont, sobre el riu, les va rebre el clero de la ciutat, una entusiasta multitud, la banda de música, i l'Ajuntament en ple presidit per l'alcalde, l'advocat Buenaventura González Peris, pare del també lletrat José González Melo. Les monges van ser conduïdes sota pal-li fins a l'església del Salvador, on es va celebrar una Eucaristia en acció de gràcies per la seua arribada. En l'organització d'esta càlida acollida va tindre molt a veure el rector mossén Joaquín Jardí Llangostera, qui va posar gran entusiasme perquè tots assistiren a la recepció i posterior processó fins al nou edifici. Els actes van constituir un clamor popular d'adhesió a la nova comunitat religiosa.

Eixe mateix dia, festivitat de la Mare de Déu del Carme de 1890, va quedar constituïda la Comunitat de Monges Dominiques de Borriana.

El nou monestir es posava davall l'advocació i el patrocini de la Sagrada Família per exprés desig dels seus fundadors, esperançats a enfortir els fonaments de la família cristiana. Les monges oferien el seu compromís d'orar amb interés per la salvaguarda de les famílies del poble.

Va quedar així tancada la comunitat animada a oferir la seua vida i la seua perpètua oració a un propòsit venerable: la família.

I la vida monàstica va començar a Borriana. Vida que, després dels seguicis de benvinguda, va passar a la foscor i el silenci dels qui s'amaguen en Déu per a aconseguir la seua missió. Vida austera i modesta de qui ho deixa tot per a trobar la seua felicitat en Déu.

No obstant això, no podia quedar arraconada la idea de construir-hi una nova església. Tant la comunitat com els sacerdots fundadors tenien esta aspiració. Era necessari un lloc especial per a orar, celebrar la litúrgia i participar amb el poble del culte a Déu. La idea era que fora àmplia, ja que la resta de les esglésies de Borriana quedaven distants, i els fidels del barri cada vegada n'eren més, atés que el poble havia començat a expandir-se al voltant del convent.

Esta vegada va ser José Ramón Monserrat qui li va comprar a Elvira González una altra part de la seua finca de la partida de València per a donar-la a la comunitat. A pesar d'això, l'altre fundador, Juan Bautista Llopis, no va poder veure culminada la seua obra, ja que va morir a Madrid l'any 1892.

El dia 26 d'agost de 1894 es posava la primera pedra de l'església, i immediatament va començar la seua edificació a costa del dot de diverses monges, que van obtindre autorització expressa per a poder destinar-lo a les obres.

L'edifici del temple va resultar així: una àmplia nau neoclàssica de 52 metres de longitud per 13 d'amplària amb volta de llunetes. Dividida per cinc pilars, que creuen la volta com a arcs faixons i dividixen la nau en set trams, corresponents els dos primers al cor alt i l'últim i més profund al presbiteri i altar major. En la part més alta de les parets laterals 
cinc finestrals circulars en cada costat ajuden a la il·luminació de tota l'església. Presidix, sobre l'altar major, un grup escultòric de la Sagrada Família, i als seus costats, en els llenços laterals, dos tribunes amb gelosies per al res privat de les monges. Entre els pilars de la nau restava la possibilitat d'unes capelles laterals molt poc profundes que, gradualment, van quedar presidides per distintes advocacions amb les seues imatges.

La façana es quedarà per sempre amb la rajola vista. Un gran frontó emmarca, en la part més alta, l'arrancada de la façana. Tres estilitzats i airosos finestrals donen la llum al cor alt. Una única porta amb llinda de rajola queda emmarcada per un parell de fines columnes. La teulada, a dos vessants, deixa en el vèrtex que mira a la façana una espadanya amb dos xicotetes campanes que encara sonen per a reunir els fidels en la celebració eucarística.

A l'ombra de la canonització de sant Martí de Porres, i per a acomodar el monestir a les noves exigències litúrgiques emanades del Concili Vaticà II, en 1964 va poder inaugurarse un nou cor, perquè les monges, tant en la litúrgia de les hores, com en la celebració eucarística, estigueren en contacte directe amb l'església, l'altar i el sagrari.

\section{SANT MARTÍ DE PORRES}

Capítol a part mereix sant Martí de Porres: el sant de la granera.

El Beatet, com és conegut a Borriana, és el que des del punt de vista devocional s'emporta la palma. Des que la seua imatge va arribar a la nostra ciutat en 1954, gràcies al pare Antonio Huguet Montoro, i a una agraïda devota, Pilar Fuch, centenars de borrianencs oren davant de la seua imatge, en especial els que van i venen del Centre de Salut.

El 2 de febrer de 1957, l'aleshores bisbe de Solsona, monsenyor Vicent Enrique i Tarancon, va consagrar als peus de la imatge del beat Martí un nou altar, i en 1962 va arribar la notícia de la seua canonització per part del papa Joan XXIII. Des d'aquell any, la devoció ha continuat en extensió i en profunditat. L'església de les Dominiques és l'única que roman oberta tot el dia perquè durant tota la jornada se succeïxen les visites piadoses al sant mulat. Les animetes enceses ofrenades pels devots il·luminen sense interrupció el temple, es veuen les imatges del sant en cotxes, llars i devocionaris. Cada 3 de novembre se celebra la festa d'este sant peruà, dia en què la imatge del sant ix en processó es repartixen centenars de panets beneïts.

Les dominiques, a pesar de la seua clausura, sempre han estat pròximes a la realitat de Borriana. Mostra d'això és que van tindre obert un collegi entre 1928 i 1961, excepte l'obligat parèntesi de la Guerra Civil.

En 1959 van accedir a emetre per ràdio el res del rosari a través de La Voz de Burriana. Totes les vesprades eixien a l'aire a través dels micròfons de l'emissora local. Amb el cant gregorià de la Salve Regina tancaven les emissions, que es van estendre a misses i processons. D'esta manera facilitaven, principalment als malalts, la paraula sonora de resos i predicadors.

Un altre vincle, sens dubte, el constituïx la Germandat de l'Eccehomo, la imatge de la qual es mostra en processó des de 1964 en la nostra Setmana Santa.

Ja recentment, arran dels primers fenòmens migratoris, les monges van donar testimoni directe de la seua solidaritat repartint diàriament entrepans entre els més necessitats a les portes del convent. 
Amb l'arribada de les monges a Borriana va nàixer una llarga llista de vocacions dominiques a la nostra ciutat, entre les quals destaquem el pare Vicente Monserrat Meliá (nebot d'un dels fundadors), el pare Manuel Fortea Soler, els germans Huguet Montoro: Antonio, Terencio María i Francisco; Manuel María Gual Esteve o fra José Huguet, nebot dels tres pares Huguet Montoro.

\section{El convent de Sant Josep dels pares carmelites}

Des del passat 6 d'octubre de 2019 la Comunitat de Carmelites Descalços de Borriana ja no es troba entre nosaltres, després de cent vint-i-tres anys de presència ininterrompuda de l'orde en la nostra ciutat.

La influència dels carmelites s'estén com una taca d'oli a causa dels milers de xiquets i jóvens que van passar per les aules del col-legi Niño Jesús de Praga, convertit hui en el collegi Illes Columbretes.

En els nostres camins rurals abunden les fornícules i ceràmiques amb la imatge de la Mare de Déu del Carme, clara evidència de la devoció que li professen molts borrianencs.

La presència dels carmelites en la nostra província cobra sentit des d'eixe focus d'espiritualitat que és el convent del Desert de les Palmes, fundat en 1694, que va començar sent un monestir de vida exclusivament contemplativa i que en l'actualitat és el noviciat on inicien la seua vida religiosa els futurs carmelites de tota la península.

Des del segle XVIII els carmelites del Desert posseïen una finca de 54 fanecades en el lloc conegut com les Alqueries de Ferrer, en el terme de Borriana. Esta finca procedia d'una donació feta a la comunitat i que van mantindre en propietat fins a la desamortització de Mendizábal en 1836. Allí hi havia una capella, que encara existix, dedicada a la Sagrada Família. La campaneta primitiva, amb el nom Mare de Déu del Carme, encara es conserva.

Després de la supressió dels ordes religiosos masculins a Espanya i la desamortització dels seus béns, allà cap a l'any 1836, no van faltar intents de recuperar novament la vida religiosa. El record, encara viu en la Plana, del Desert de les Palmes i la proximitat del convent carmelita de la Sagrada Família de Nules, fundat en 1673, i que després d'un llarg període d'inactivitat ja havia sigut entregat a les monges clarisses, va fer pensar en la ciutat de Borriana per a crear una nova fundació. En l'orde eren molts els borrianencs que gaudien de prestigi, i des d'un principi es van brindar a donar tot el seu suport espiritual i material perquè la comunitat s'establira a Borriana.

A principis de 1896 un grup de carmelites es va instal-lar provisionalment al carrer de Sant Agustí, número 12, en una casa de Francisco Granell Peset, iaio de l'empresari Francisco Granell Felis, propietari i fundador de la Paperera del Cid i president del Banc de Borriana.

El 26 d'abril d'eixe mateix any va poder posar-se la primera pedra del nou convent. Poc més de sis mesos van bastar per a fer habitable la planta baixa i crear-hi una capella provisional.

Finalment, el 6 de novembre de 1896 es va fundar canònicament la Comunitat dels Carmelites Descalços de Borriana, de la qual va ser nomenat primer prior el pare Modesto del Sagrado Corazón de Jesús (Manuel Huguet Ferrer), fill de Borriana. 
Des del primer moment es va programar un conjunt conventual perfecte, complet, tal com s'exigia per a esta classe d'edificis. El solar comprenia 7.045 metres quadrats. Es va dissenyar un espai ampli per al convent, horta i pati interior, i un altre per a l'església de culte. Mai hi va haver un projecte inicial de col·legi, encara que les successives modificacions es van fer amb vista als nous usos i necessitats.

La mà generosa dels primers benefactors i fundadors es va desbordar ja des dels començaments. El solar va ser adquirit per Vicente Ramón Felis Oliver, Bernabé Peris Enrique, Antonio Albesa Peris i l'advocat Enrique Peris Enrique. Però una vegada iniciades les obres, qui es va convertir en el principal benefactor i protector de la Comunitat, amb el suport del seu germà Jeremías, va ser el comerciant Bernabé Peris, el qual va voler construir la seua sumptuosa residència alhora que s'alçava el convent (actual Camí d'Onda, núm. 1).

Bernabé, a més de ser un pròsper comerciant, era un home molt piadós, gran devot de sant Josep, la imatge del qual tenia molt present en el seu magatzem i en sa casa. Tal era la veneració que per a justificar les seues destacades aportacions per a la construcció del convent solia dir: «Forme societat amb sant Josep; jo pose el treball material, el sant patriarca la seua intercessió, i Déu beneïx el nostre comerç; per consegüent, és just que tinguen una part en les utilitats». El dia que va inaugurar sa casa, pocs mesos abans de morir, a l'edat de 40 anys, va assentar a la taula dotze desheretats que va arreplegar pel carrer i va posar unes estovalles amb un escut, que encara existix, en el qual es podia llegir: facta non verba (fets, no paraules).

El benefactor va morir el 4 de juliol de 1900. En la seua necrològica publicada en El Correo Español assenyalaven: «Falleció este insigne carlista y ferviente católico valenciano en la villa de Burriana (...) por lo que se aplicarán en sufragio de su alma todas las Misas que se celebren en la parroquia y en el convento de los Carmelitas descalzos a cuya fundación contribuyó más que nadie el difunto».

Bernabé Peris va ser el primer exportador que va utilitzar paper de seda per a embolicar les taronges. La seua marca en les caixes de primera era: «Dios, Patria y Rey». Un altre dels seus grans propòsits era afavorir les vocacions religioses, fins al punt de pagar el dot a les jóvens que prenien l'hàbit. Els seus treballadors, en general, li tenien en gran estima, perquè a molts els va pagar la redempció en metàl-lic perquè no feren el servici militar a Àfrica.

A finals del segle XIX va protagonitzar un enfrontament amb Vicent Blasco Ibáñez que va ser molt comentat durant dècades. El 13 de setembre de 1899, a l'estació del tren, van coincidir Blasco Ibáñez, que venia per a assistir a un míting republicà, i el carmelita P. Ludovico per a prendre possessió com a segon prior del convent. Segons va relatar el Diario de Castellón, els fets van ocórrer de la següent manera:

«Las luchas religiosas estuvieron a punto de hacer ayer a la importante ciudad de Burriana, teatro de sangrientos sucesos.

En el mismo tren que conducía a Burriana a Blasco Ibáñez y otros republicanos valencianos para asistir al meeting que se celebraba aquella noche en el Círculo republicano, iba el Rdo. P. Liborio - (en realitat era Ludovico) - , también con dirección a Burriana.

En la estación esperaban a Blasco algunos republicanos, y al padre carmelita el conocido carlista y rico propietario de dicha villa don Bernabé Peris y algunos amigos. Estos últimos iban armados. 


\begin{abstract}
Al apearse Blasco Ibáñez se dio un viva a la República y entonces el Peris y sus amigos contestaron con un viva al Corazón de Jesús.

En el trayecto de dos kilómetros que media de la estación al pueblo, fueron encendiéndose los vivas de uno y otro lado, pero habiéndose adelantado los carruajes en el que iban el señor Peris y sus amigos, se detuvieron en la soberbia casa que este posee a la entrada del pueblo y allí arma al brazo esperaron la llegada de los republicanos.

Lo que ocurrió allí en un momento es imposible describirlo: en manos de unos y otros se vieron relucir brillantes hojas de acero, armas de fuego cortas y largas y en uno y otro lado a personas que procuraban contener a los más decididos. Venció la razón y unos y otros abrieron paso marchando los republicanos al Centro y los carlistas a casa del señor Peris.

Resultaron tres heridos, uno en la ceja de un mordisco, otro en un pie de una pedrada y otro en la mano de una cuchillada que se infirió al tratar de evitar mayores males.

Durante todo el día reinó gran excitación y temores de que se reprodujeran los sucesos de la tarde.

En el meeting hubo mucha gente, pero sin duda no tenían simpatías por las ideas de Blasco Ibáñez, cuando al plagiar éste a Zola, por la significación del Sagrado Corazón de Jesús, demostró el auditorio su disgusto siseando al orador».
\end{abstract}

Bernabé Peris era casat amb María Rosa Calbet Moros, amb qui va tindre onze fills, dels quals van sobreviure cinc filles.

En el claustre del convent no es va arribar a realitzar el projecte original, atés que preveia lluir-lo amb algeps d'arcs, columnes i voltes. Gràcies a eixa privació hui en dia apareix al natural la bellesa de la rajola. La serenitat i l'encant del claustre ha atret des de sempre tots els que l'han admirat, fins al punt de servir com a plató de rodatge diverses vegades, com en 2005 en la pelllícula Vida robada del director borrianenc Vicent Monsonís.

Els primers habitants van alternar la vida de comunitat amb les exigències dels seus compromisos pastorals. Molt enjorn, una campaneta els convocava al cor per al res de Prima. Seguia després l'oració mental, acte important per al carmelita descalç; poc després tornava a tocar la campana per a la missa conventual. Encara es conserva la xicoteta espadanya de la fundació sobre les cellles actuals, damunt de la capella provisional. La gent de Borriana, els més matiners, acudien a eixa missa de sis del matí.

Encara ni un raig de sòl desvaneix l'hòra de l'alba i al nou día li fan salva de pardalets un estol, qu'envien alçant el vòl del pòble a les quatre cares, eixes armonies rares, que al pòc rato les altera la campaneta dels frares tocant a missa primera. (sic) 


\section{EL TEMPLE}

La Comunitat va encarregar en 1897 al destacat arquitecte de Castelló Godofredo Ros de Ursinos, un projecte per a edificar l'església. El resultat van ser dos bonics treballs d'estil neogòtic, dels quals es va rebutjar un.

El projecte que no va arribar a executar-se es troba actualment en l'arxiu de la Diputació de Castelló, i destaca per dotar de major rellevància l'entrada situada en el carrer de Sant Joan de la Creu, amb un pòrtic de triple arcada sobre el qual s'eleva una única torre. L'església quedava articulada en tres naus, amb capelles laterals, la central de major altura per a il-luminar-la amb grans vitralls. També projectava una capella de la comunió darrere del presbiteri i un sistema de contraforts semblant al ja executat per este arquitecte en l'ermita de Santa Bàrbara en 1891.

Finalment, es va optar per un altre projecte d'una sola nau, amb quatre torres, que emfatitzava la façana que dona al camí d'Onda, on quedava situat l'accés a l'església. L'1 de maig de 1898 es va collocar la primera pedra del temple, que posseïx una nau de $47 \mathrm{x}$ 20 metres amb creuer central, nou altars i una alçària de 22 metres.

En 1903 la construcció del temple aguaitava a flor de terra. Les obres van quedar suspeses quan s'havien construït els fonaments i els murs tenien tres metres d'alçària. En el període de 1904 a 1914 van prosseguir les obres de l'església, però a un ritme molt irregular, ja que depenia de les aportacions econòmiques. La defunció del principal benefactor, Bernabé Peris, va ser, sens dubte, un seriós contratemps, a pesar que la seua dona va continuar ajudant l'obra de manera significativa.

Superada la crisi econòmica ocasionada per la I Guerra Mundial, de nefastes conseqüències per al negoci taronger, la fàbrica del temple va recobrar un nou impuls. Al maig de 1924 es van reprendre les obres i es va aconseguir l'altura dels arcs. No obstant això, el 16 de setembre d'eixe mateix any va morir l'arquitecte, a l'edat de 74 anys, i es va fer càrrec de la direcció de les obres el projectista valencià Alfonso Garín Ortolá, que havia sigut col-laborador de Godofredo. Alfonso Garín va introduir alguns canvis en el sistema de construcció, en la distribució interna i sobretot en l'emplaçament de la porta principal, que Ros de Ursinos havia previst originàriament en el creuer, en la zona situada davant del quiose del Camí d'Onda.

Al maig de 1927, la Comunitat, recolzada pel nou provincial, el P. Bernardino de Jesús y María (Francisco Claramonte Felis), fill de Borriana, va decidir accelerar les obres, cobrint-la i obrint-la al culte després de tants anys d'estar començada. Era prior el P. Alfonso de la Inmaculada, i superior el P. Gonzalo de Santa Cecilia (José Huguet Diago) també fill de Borriana.

Per a poder fer front a les despeses, la Comunitat es va veure obligada a formalitzar un préstec amb el Banc Hipotecari de 100.000 pessetes, que va acabar de pagar en 1956. I això, a pesar de l'alé econòmic de piadosos benefactors que van sufragar imatges i altars, com la família Llopis Brugada el del Sagrat Cor de Jesús, o la família Feliu Granell el del Santíssim Crist Crucificat.

El 17 d'abril de 1929 es va beneir i inaugurar l'església, en una solemne cerimònia presidida pel bisbe de Tortosa, Félix Bilbao Ugarriza, acompanyat pel bisbe de León (Mèxic), Emeterio Valverde Téllez, perquè cal recordar que entre 1920 i 1936 en el carrer 
de la Mercé va haver-hi una comunitat de monges carmelites que havien sigut expulsades del seu país per la revolució.

Solemnes cultes i actes culturals i populars van acompanyar la celebració. Per Borriana van passar eixos dies grans figures de l'oratòria i de la cultura. El poble sencer es va vestir de gala per a celebrar l'esdeveniment. La primera missa, a la qual va acudir la corporació en ple, presidida per l'alcalde, Vicente Enrique Mingarro, va estar amenitzada per la capella de música del Convent dels Carmelites Descalços de València, integrada per més de seixanta veus, i pel violinista borrianenc Abelardo Mus.

A la vesprada es va celebrar una grandiosa processó per al trasllat del Santíssim Sagrament des de la capella provisional, habilitada en 1896, fins a l'església. La custòdia, sota pal-li, va recórrer diversos carrers de Borriana, en els quals es van alçar magnífics arcs i altars.

La Comunitat havia aprovat el 30 de gener de 1908 construir esta custòdia, que actualment es troba en el museu del Desert de les Palmes. El treball va ser encarregat a l'orfebre Manuel Orrico, de València, qui va encarregar l'emmotlament dels apòstols que rodegen el viril al jove artista castellonenc Juan Bautista Porcar.

Este admirable ostensori va ser sufragat amb almoines i objectes de plata i or oferits pel poble de Borriana, i posseïx en el viril diverses joies de la reina Maria Cristina d'HabsburgLorena, donades a través del pare Salvador de la Madre de Dios, provincial de l'Orde, que en aquells moments exercia de confessor reial.

El 20 de gener de 1930 la Comunitat va publicar un fullet commemoratiu d'este esdeveniment, en el qual es podia llegir:

«Infatigable constancia, abundantes sudores, esfuerzos porfiados, treinta años de trabajo y sacrificios fueron necesarios para levantar el Templo de San José. No pareció, sino que la Providencia se complacía en probar y aquilatar la perseverancia de los que en ella confiaban antes de acceder a sus nobilísimos y vehementes deseos. Pero, al fin, salió triunfante la perseverancia...

Como de improviso y por arte de encantamiento vimos erguirse las columnas, coronarse los capiteles, entrelazarse los arcos, extenderse las bóvedas, surgir, en una palabra, el templo con toda su grandeza y majestad»

L'artista valencià Jesús Salarich va dur a terme l'emmotlament i buidatge de capitells, frisos, rosetons, balustrades, púlpits, altars i finestrals. Els mateixos tallers de Salarich es van fer càrrec, després de la guerra, de construir l'actual retaule de l'altar major, en ciment i escaiola.

El paviment de l'església i de la sagristia, de taulells hexagonals de diverses tonalitats, formant dibuixos geomètrics, va ser construït i collocat pels operaris de la fàbrica de mosaics de Pablo López, de València.

Originàriament, l'església va tindre dues trones laterals de pedra artificial en florit estil gòtic, regalades pel patrici borrianenc Manuel Peris Fuentes, benefactor del col-legi dels Salesians.

Tres torres van quedar inacabades, i en 1971 es va decidir continuar la seua construcció (a excepció de les agulles, que mai van arribar a edificar-se). L'arquitecte borrianenc 
Alfonso Saera Monfort es va encarregar del projecte i de la direcció de les obres, que van ser executades per l'empresa constructora de Pascual Molés i Ramón Llopis.

En la torre sud-oest, que era l'única acabada abans de 1972, s'havien instal-lat l'any 1949 tres campanes vigoroses durant el priorat del pare Aurelio, natural d'Almassora. Les campanes, que han voltejat durant setanta anys, porten per nom Carmen Teresa, la major, Josefina i Niño Jesús de Praga.

En el nou temple, inaugurat el 17 d'abril de 1929, es van colllocar talles d'imatges fetes pels artistes valencians Francisco Pablo Panach (autor del pas del Sant Sepulcre de Borriana) i Francesc Cuesta López. Transitòriament, en l'altar major, va ser col·locada la imatge de sant Josep de la capella provisional. D'esta imatge encara es conserva el xiquet en el convent de les Mares Carmelites Descalces de les Alqueries, fundat en 1957 per mossén Jeremías Melchor Esteve.

Al març de 1936 va ser col·locada la imatge central de sant Josep amb el xiquet de la mà muntat sobre un núvol i sostingut per dos àngels agenollats en actitud orant, obra de l'escultor carmelita germà Francisco del Niño Jesús, Justo Vivó Huguet. Una obra de grans dimensions, perquè només la imatge tenia tres metres i el grup un total de cinc. Destruïda al juliol d'eixe mateix any, va ser l'obra mestra del germà, llaurada al seu taller del convent. En la cerimònia de col·locació va estar present el seu mestre i amic, l'escultor valencià José María Ponsoda Bravo.

La majoria dels objectes religiosos, imatges i altars, van quedar completament destruïts en el saqueig del 26 de juliol de 1936. Abans van poder amagar-se alguns objectes molt valuosos com la custòdia, el tern, el vestit i el mantell de la Mare de Déu, les escriptures del convent i altres documents de la fundació. A Borriana hi havia una escola de brodats dirigida per sor María Huguet Ferrer, religiosa de la Consolació, germana del primer superior, el P. Modesto del Corazón de Jesús, i tia del P. Gonzalo de Santa Cecilia. Allí es van perfilar els millors brodats per al culte de l'església dels Frares.

Imatges, bancs, confessionaris..., van ser destruïts i portats en un camió fins al llit del riu, on una gran foguera va consumir les restes de fusta.

Eixe mateix dia, l'Agrupació Socialista Obrera va ocupar l'església i el convent i el va convertir en un centre social al servici del poble. Allí es va instal-lar un casino, bar i oficines, i va funcionar com a sala de balls i banquets. Una gran fotografia de Pablo Esglésies Posse presidia el que havia sigut l'altar major. El convent, separat de l'església, va ser destinat a alberg de tropes i evacuats, així com a hospital i manicomi.

A mesura que s'aproximava el front, van començar a créixer els bombardejos aeris, motiu pel qual en 1938 es va construir un refugi antiaeri, actualment en fase de rehabilitació, l'accés del qual està situat just davant de l'entrada de l'església, convertida en aquells anys en Casa del Poble.

Després de la contesa, i gràcies a les aportacions de nombrosos confrares, el temple de Sant Josep es va convertir en un autèntic museu d'art religiós. Entorn d'estos monestirs o convents sempre han sorgit grups de fidels que han participat assíduament del culte, de les seues activitats, inclús de la seua direcció espiritual. Ja en 1900, poc després de la fundació, es va organitzar la confraria Virgen del Carmen, que va arribar a tindre 4.000 confrares; la confraria Niño Jesús de Praga, la Piadosa Unión de Santa Teresita, l'associació de l'Escapulario Josefino, o la més recent, la Hermandad de la Virgen de la Piedad, creada 
en 1963 pel pare Leopoldo Blanch amb un grup d'antics alumnes del col·legi Niño Jesús de Praga, que participa activament en les nostres processons i el culte de la Setmana Santa.

L'església dels Pares Carmelites de Borriana compta actualment amb una de les colleccions imatgeres més completes dels mestres valencians Carmelo i Octavio Vicent. Ambdós - pare i fill- van enriquir esta església amb més d'una dotzena d'obres eixides del seu taller del carrer de la Blanqueria de València.

Carmelo Vicent, catedràtic de talla escultòrica en l'Escola de Belles Arts de València i Premi Nacional d'Escultura en 1934, va ser l'autor de la joia principal d'esta església: la imatge de la Mare de Déu del Carme, una obra de gran qualitat artística.

A la seua mà es deuen també les imatges del Cor de Jesús i de Sant Joan de la Creu.

El seu fill, Octavio Vicent, catedràtic de l'Escola de Belles Arts de València i, més tard, catedràtic de l'Escola de San Fernando de Madrid, està representat en l'església amb altres set obres, reunides quasi totes en l'altar del Jesuset de Praga. Els sis relleus d'este retaule al-lusius a la infància del Jesuset, el mateix que els altres sis que adornen el retaule de la Mare de Déu del Carme, ens donen una clara idea del sentit del ritme i la composició d'este gran escultor format en les escoles de Madrid, Florència i Roma.

La talla del Jesuset de Praga i la xicoteta imatge de la Nostra Senyora de Loreto, completen la seua aportació al retaule lateral dret de l'església.

Tal vegada l'obra més important d'Octavio Vicent siga la Mare de Déu de la Pietat, obra realitzada en 1965, que representa Jesús mort en braços de la Mare de Déu. Esta imatge, de profunda expressió religiosa i gran sobrietat pictòrica, va ser encarregada per la Germandat de la Pietat, i és el pas d'esta confraria en les processons de la Setmana Santa de Borriana.

Este mateix artista havia fet, en 1959, la carrossa en forma de barca de la Mare de Déu del Carme per a les processons, que des de fa anys es troba a Caravaca de la Cruz, on ix en processó cada 16 de juliol.

Entre els objectes d'orfebreria, a més de la custòdia, que es troba en el museu, mereix destacar-se la creu processional i, especialment, el sagrari, obra de Vicente March Bernal.

En 1962, i promogut pel pare Leopoldo, es van collocar les vidrieres que decoren el temple. Cada una està formada per dos cossos: un inferior, dedicat als dolors i gojos de sant Josep, i un altre superior amb temes relatius a l'orde carmelità. A part de dos grans rosetons, corresponents a les capelles de la Mare de Déu del Carme i el Jesuset de Praga, hi ha una gran vidriera en la part del cor que mostra en la seua part inferior una escena de la Sagrada Família, i en la superior, una al-lusió a la protecció de sant Josep sobre la ciutat de Borriana, representada pel campanar i l'edifici de la Caixa Rural Sant Josep. Les vidrieres són de la casa Maumejean de Madrid, empresa familiar fundada en 1860.

\section{COL·LEGI}

Encara que com hem dit: mai hi va haver un projecte inicial de collegi, des del primer moment de la fundació els religiosos de Borriana van haver de dedicar-se de ple a la tasca docent.

Dos mesos després de la seua aprovació canònica, el 25 de gener de 1897, la Comunitat va crear un seminari menor, al qual van succeir un collegi de teologia, en 1902, i un altre de filosofia en 1904. 
L'11 de desembre de 1907 la Comunitat va aprovar la creació d'una escolania a fi de preparar xiquets i jóvens per a fer representacions escèniques i assistir al culte de l'església.

Encara que des de les altes esferes no es veia amb bons ulls, per entendre que era impropi de l'orde, els religiosos no van tindre més remei que atendre les sol-licituds de pares de família que els buscaven per a donar classes particulars als seus fills. Borriana, en eixos moments, no tenia col-legis suficients. A més, el seu ràpid creixement econòmic, gràcies al negoci taronger, empentava els pares a buscar la millor formació per als seus fills.

Els religiosos estaven àmpliament preparats. Comptaven amb una sòlida formació, tant en lletres com en ciències.

Així les coses, el P. Bernardino de Jesús María, definidor i visitador general, en un viatge que va fer a Borriana en 1920, va rebre una nodrida comissió de ciutadans, pares de família, que li van demanar amb insistència l'obertura d'un col-legi per a xiquets. Un any després d'aquella reunió, el Capítol Provincial va autoritzar la creació d'un col·legi de primera ensenyança. I així va ser com va iniciar el seu camí el collegi Niño Jesús de Praga.

Diverses generacions de xiquets i jóvens s'han beneficiat de la formació cultural i espiritual dels Frares. El colllegi va suposar per a ells l'oportunitat d'accedir a una educació integral. Durant dècades, i en perfecta sintonia, el claustre de professors i els pares carmelites, van omplir de contingut acadèmic i valors humans a les distintes promocions que van passar pel centre.

El collegi dels Frares va nàixer de forma modesta, i amb el temps es van anar ocupant zones del convent per a transformar-les en aules.

La coneguda com a porta del col-legi és la que encara es conserva actualment pel carrer dels Frares. Anys després va aparéixer la porta del pati, en el carrer de Sant Joan de la Creu, on encara s'alça l'escut carmelità.

El pati actual, on juguen els xiquets, era l'horta en què sembraven els frares, i a causa de les necessitats del col-legi va haver de desaparéixer perquè la utilitzaren els xiquets $i$ els jóvens.

Des del moment de la creació del col·legi les modificacions es van fer segons les necessitats de cada moment. Però va ser l'any 1966 quan el convent va patir la seua gran transformació. Era l'època en què estava de director el pare Manuel Ferrada. Les terrasses dels costats nord i oest van desaparéixer i només els costats sud i est van romandre en el seu estat original. Van ser unes obres necessàries perquè els Pares Carmelites pogueren sol-licitar la implantació i el reconeixement del batxillerat, aprovació que va arribar el 15 de juliol de 1967. Fins llavors s'impartien les classes en el col·legi i els exàmens finals es realitzaven a l'Institut Francesc Ribalta de Castelló. A partir de l'any 1966 es van realitzar diverses obres en què van intervindre els arquitectes José Manuel Peris Gómez, Manuel Peset Ninot, Alfonso Saera Monfort, Lauro Negre Hernández, Pascual Molés Cantos, i l'aparellador Joaquín Albert Serra.

\section{TEATRE}

La projecció cultural dels Carmelites va traspassar els murs del convent i una de les seues grans fites va ser la construcció de la sala d'actes Niño Jesús de Praga en una part del que era l'horta del convent. La seua inauguració, el 18 d'abril de 1929, va coincidir 
amb la benedicció del temple de Sant Josep. La sala ocupava una superfície de 30 x 15 metres i tenia una capacitat per a 1.600 persones. Borriana sencera es va sentir orgullosa d'aquell gran centre cultural per la seua bellesa i grandiositat. Però als carmelites els va durar poc, perquè al cap de dos anys, per necessitats econòmiques, el van vendre a la família Safont Casares, motiu pel qual va passar a anomenar-se Teatro Casares, en honor a la matriarca: Antonia Casares Rius, natural d'Alboraia. Uns anys més tard, i després de vendre's novament, va passar a denominar-se Teatre Principal, fins a la seua demolició, en 1992, per a construir un bloc de pisos.

A pesar de tot, els carmelites van continuar organitzant allí les seues activitats culturals, com el recordat Betlem del pare Alberto de Jesús. Este frare s'encarregava dels xiquets de pàrvuls i tot just arribar a Borriana va començar a organitzar i dirigir representacions literàries i musicals, entre les quals destacava el seu betlem nadalenc, que tenia com a intèrprets els mateixos xiquets. Tal va ser la magnitud i l'èxit aconseguit que va arribar a representar-se l'obra en el Teatre Principal de Saragossa en 1943 i en el de València en 1944. Estes representacions van durar quinze anys, i fins a la seua defunció en 1936, el pare Gonzalo va ser l'encarregat de posar la nota musical, atés que era l'autor de tota la partitura del Betlem.

A més del pare Alberto, altres carmelites que van transcendir més enllà de la Comunitat van ser el pare Roque Guinot Pitarch, gran pintor i amic de pintors. Asseguren que va arribar a posseir apunts genuïns de Miquel Àngel, i d'altres artistes de renom, que li va proporcionar el marqués de Santa Cruz, gran mecenes amb qui compartia amistat. El pare Roque va morir el 24 de juny de 1936, tres setmanes abans que s'iniciara la Guerra Civil, i està soterrat en el panteó dels carmelites, en el cementeri de Borriana. El pintor castellonenc Juan Bautista Porcar, que exercia en aquell moment de delegat de Cultura del Govern Civil de Castelló, quan es va assabentar que el convent havia sigut assaltat el 26 de juliol de 1936, es va afanyar a anar a Borriana, coneixedor dels dibuixos originals que posseïa el pare Roque. Tota la seua vida va lamentar no haver-hi arribat a temps, perquè allí ja no hi va trobar res.

Un altre referent va ser el pare Gonzalo de Santa Cecilia, José Huguet Diago, fill de Borriana. Va ser prior del monestir i superior diverses vegades. Era nebot del P. Modesto Huguet, primer superior de la Comunitat. Excellent executor de música sacra, va compondre també notables peces que li van donar no poca fama, principalment en els cercles religiosos espanyols. Es conserva el seu arxiu amb diversos originals que ell va compondre i moltes de les obres que interpretava. Actuava com a pianista i concertista de la sala d'actes Niño Jesús de Praga i en un tercet de música de cambra acompanyat per Vicente Doménech, al violí, i Vicente Soler, al violoncel. Va ser una de les víctimes de la Comunitat a l'estiu de 1936.

També va ser un destacat artista el germà Francisco del Niño Jesús, Justo Vivó Huguet, natural d'Alboraia. Ajudant i deixeble durant molts anys de l'escultor José María Ponsoda Bravo. Tenia taller propi en el convent i va realitzar una infinitat d'imatges religioses, repartides per tota la geografia espanyola. En el Desert de les Palmes encara es conserva un Crist i un Jesuset llaurats per ell. Però la seua obra cimera va ser el sant Josep de l'altar major del temple de Borriana, que formava part d'un grup de cinc metres. La imatge central de sant Josep va ser beneïda i colllocada en l'altar major la vespra del sant, el 18 de març de 1936. No hi ha cap fotografia d'aquell sant Josep perquè quatre mesos més tard va ser destruït. Este germà també va ser martiritzat a l'agost de 1936. 
Un admirable renovador pedagògic va ser el pare Manuel Ferrada Urios. Doctor en Filosofia, va ser el creador de la festa de la poesia, que es va celebrar des del 1968 fins al 1976. Jóvens del collegi i d'altres centres educatius, amb inclinacions literàries, van participar d'aquells esdeveniments. El pare Ferrada va emprar la poesia, tan pròpia de sant Joan de la Creu, perquè els jóvens s'acostaren a la cultura i reflexionaren sobre els valors humans. Per aquelles reunions van passar els grans poetes valencians Vicent Andrés Estellés, Xavier Casp o Miquel Peris i Segarra, entre altres. De tot això va donar compte en el seu llibre Crits i cants, publicat en 1975. També va impulsar el club juvenil SOM, amb seu al carrer de Sant Vicent, que organitzava activitats de cine club, tallers de lectura, fotografia, classes de valencià, conferències, teatre i poesia, excursionisme, balls... Altres facetes que també va encoratjar van ser la música, a través del cant coral, i l'esport, amb jornades matinals els diumenges al matí, en les quals solia participar. Durant la seua etapa al capdavant del collegi es va inaugurar un modern gimnàs, perfectament equipat. Així mateix, va establir en el centre el programa de Promoció Professional Obrera, conegut com el PPO, embrió del que més tard seria la formació professional.

L'últim gran artista de la Comunitat va ser el pare Juan de Dios Morenilla, natural de Caravaca de la Cruz. Llicenciat en Belles Arts, tenia una gran afició per la pintura, la fotografia i el periodisme. En 1966 va ser nomenat professor de dibuix i va obrir una acadèmia de pintura que va funcionar fins a l'any 1991. Va ensenyar dibuix i pintura a molts alumnes, alguns dels quals van seguir els seus passos artístics. Gràcies a eixa labor pedagògica, durant quatre anys consecutius els seus deixebles van ser premiats en Arenzano (Gènova) en el Concurs Internacional Piccoli Artisti.

La seua obra més rellevant és el gran mural de vint-i-set metres de l'església de María Auxiliadora de Borriana, on representa la vida de sant Joan Bosco, fundador de la congregació salesiana. En l'obra van quedar immortalitzats alguns dels seus alumnes i també altres personalitats, com el cardenal Tarancon, el bisbe de la diòcesi en aquell moment, José María Cases Deordal, o el papa Joan Pau II.

Encara que mai ho van exterioritzar, la Guerra Civil, i més concretament els successos esdevinguts en la segona meitat del 1936, va suposar per a la Comunitat Carmelita de Borriana un dur colp. De catorze religiosos que hi havia en el convent la meitat van ser assassinats. La vespra del 22 de juliol de 1936 els frares van ser obligats a abandonar el monestir. Van eixir per la porta del col·legi, situada en el que llavors era el carrer del Primer Dolor, on una turba els increpava, mentre buscaven refugi a cases de familiars i amics.

Grups extremistes no van tardar a localitzar-los. El primer que va caure va ser l'escultor, el germà Francisco, Justo Vivó Huguet, natural d'Alboraia, l'11 d'agost de 1936. El varen trobar en una alqueria pròxima a la mar propietat de la família Planelles Ros; allí li van disparar i el van donar per mort. Malferit, va ser conduït per la família que l'acollia fins a l'Hospital de Sant Blai, on va ser descobert novament. Mentre el traslladaven a Castelló en una ambulància el varen rematar en la carretera d'Almassora, enfront del cementeri. Encara amb vida, el van tornar a portar a l'Hospital de Sant Blai, on va morir mentre el cuidaven les germanes de la Consolació.

L'endemà, el 12 d'agost, va morir el pare Ángel María del Niño Jesús, Bautista Broch Carda, natural de Vila-real, que llavors exercia de director del col-legi. Després d'eixir del convent es va refugiar a casa de la seua cunyada amb les seues germanes monges de la Consolació, a Vila Real, i allí el van detindre. Va ser afusellat al Grau de Castelló. 
El 17 d'agost va morir el pare Gonzalo de Santa Cecilia, José Huguet Diago: el músic. Era popularment conegut com el pare Sardina pel seu malnom familiar. Era germà del comerciant Ramón Huguet Diago, casat amb Josefa Grau Piera, cèlebre per donar sobrenom al carrer de l'Encarnació i a un bonic xalet que posseïa al port. Va ser precisament en eixa propietat on va ser capturat el pare Gonzalo, ocult en una cisterna. Traslladat amb un cotxe, el van matar al costat d'uns xiprers en la carretera d'Almassora al Grau de Castelló.

El 29 d'agost va ser detingut el que era prior de la Comunitat, el borrianenc pare Ricardo del Sagrado Corazón, Francisco Planelles Granell, a casa d'una cosina, en el número 14 del carrer del Raval, on s'havia amagat. Després de la seua detenció va ser conduït fins a la carretera que unix les Alqueries i Betxí, on va ser afusellat.

L'endemà van localitzar i executar el germà Manuel de María y José, Vicente Casalta Broch, molt conegut per ser un excel-lent cuiner. El van detindre a Borriana perquè ja s'havia cansat d'estar amagat en l'interior d'un pou d'un maset familiar de la seua ciutat natal, Vila-real, i havia decidit anar a buscar el seu prior, el pare Ricardo, amb qui va coincidir en la cella, un dia abans de ser afusellat en la tàpia del cementeri de les Alqueries.

En la matinada del 2 al 3 de setembre de 1936 va ser assassinat en la carretera de l'Alcora a Castelló el pare Jacobino del Niño Jesús, José Solá Traite. Era germà del que durant més de tres dècades va ser corresponsal de l'Heraldo de Castellón a Borriana, Rafael Solá Traite, que també era un significat republicà. Segons va declarar el mateix Rafael, el seu germà estava en l'alqueria d'una neboda situada en la Malva-rosa. Se'l van emportar i el van tancar al calabós municipal. Aquella mateixa nit va ser conduït amb altres tres persones a la carretera de l'Alcora per a ser executat.

L'últim a morir, el 12 de novembre, va ser el pare Ludovico del Sagrado Corazón, Antonio Viciedo Moreno. Uns dies abans havia sigut detingut a casa de la seua germana a Vila-real i conduït a la caserna de la Guàrdia Civil. Va morir al terme d'Onda, encara que el seu cos va aparéixer al costat del cementeri de Betxí.

Tots estos religiosos descansen en l'anomenat panteó dels màrtirs del Desert de les Palmes, i actualment estan a l'espera que el papa aprove el decret de beatificació, després d'un llarg procés, en el qual també estan incloses altres persones, com el carmelita seglar, Francisco Granell Felis, pare de Josefina Granell Vernia, qui va ser propietari de la paperera El Cid i president del Banc de Borriana, les restes del qual es troben en la cripta de l'església del Salvador.

El 25 d'abril de 2015, coincidint amb el quint centenari del naixement de Santa Teresa de Jesús, l'orde dels Pares Carmelites Descalços va rebre la Medalla d'Or de la ciutat de Borriana, una iniciativa que va comptar amb el suport de 4.000 firmes i més de cent entitats.

L'adéu a la Comunitat dels Carmelites Descalços va sembrar d'actes d'homenatge els passats mesos de setembre i octubre. Els sentiments van quedar demostrats en les nombroses mostres d'afecte dirigides al pare Alfredo Sáiz Sáiz. Un sacerdot nascut a San Martín de Boniches, un poblet de la muntanya de Conca, que va arribar per primera vegada a Borriana en 1968, i que ho ha sigut tot per a esta Comunitat: sacerdot, prior, director del col-legi... Les confraries, els professors, els alumnes..., tots van voler manifestar la seua gratitud als Carmelites per la seua gran aportació a la ciutat de Borriana. 


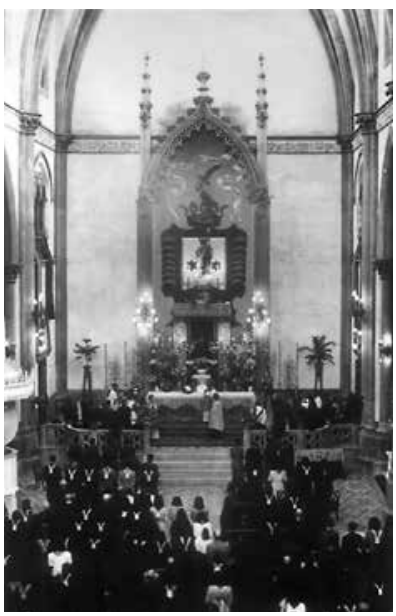

Antic altar dels frares.
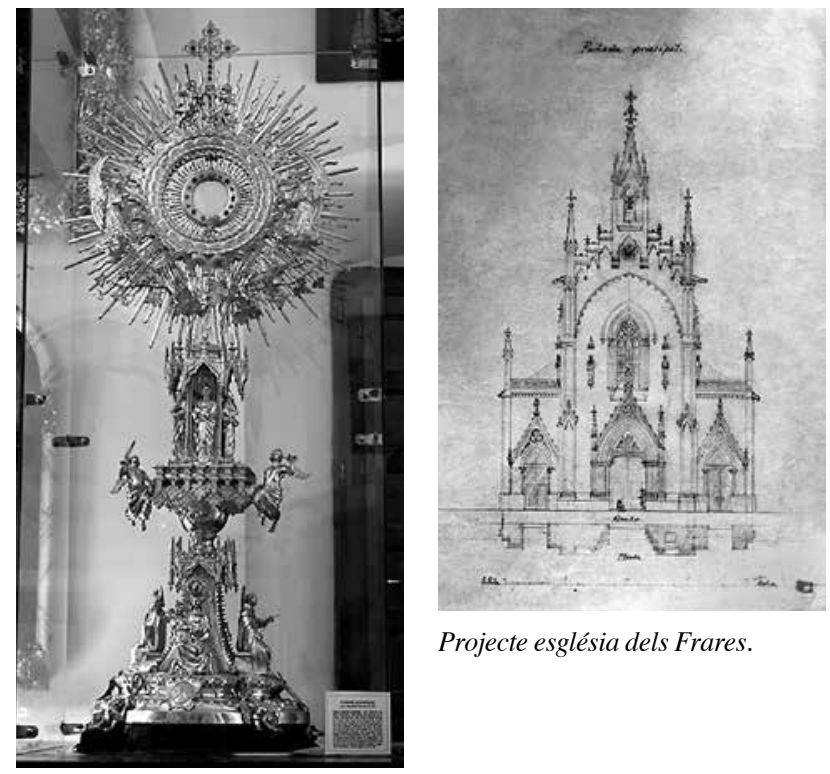

Projecte església dels Frares.

Custòdia dels frares Carmelites.

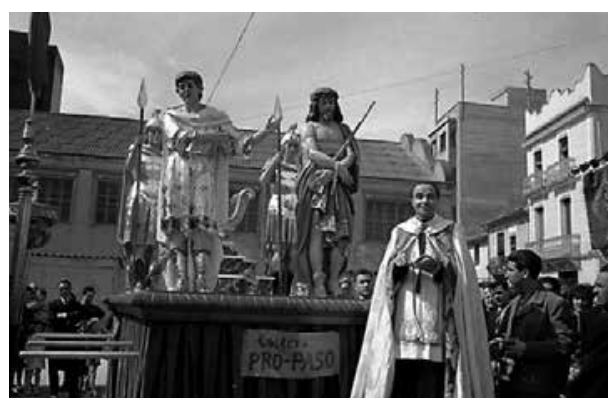

Benedicció del nou pas de l'Eccehomo a les Dominiques.

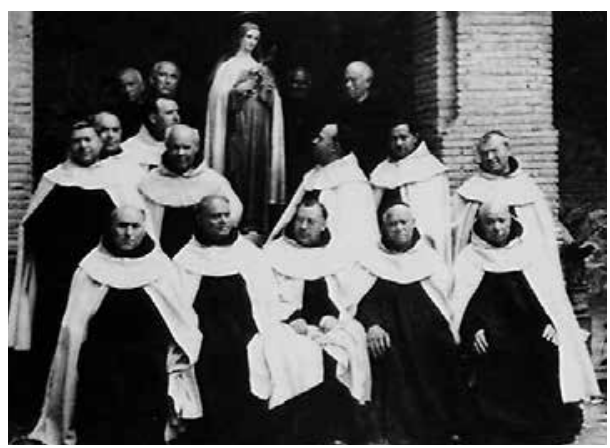

Frares Carmelites.

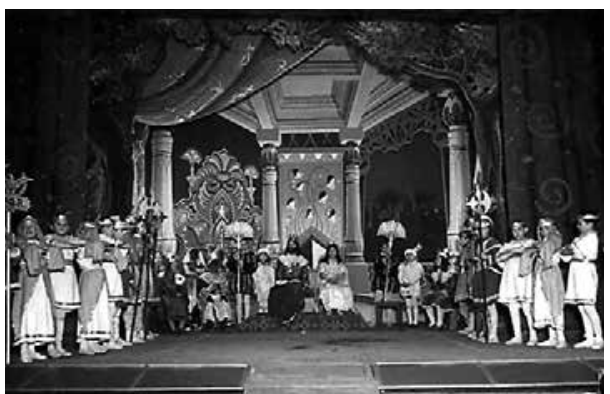

Betlem del Pare Alberto.

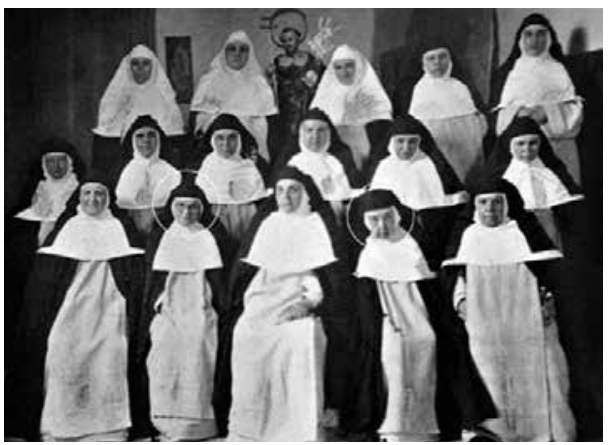

Monges Dominiques 1936.

http: //dx.doi.org/10.6035/Anuari.2020.31.9 


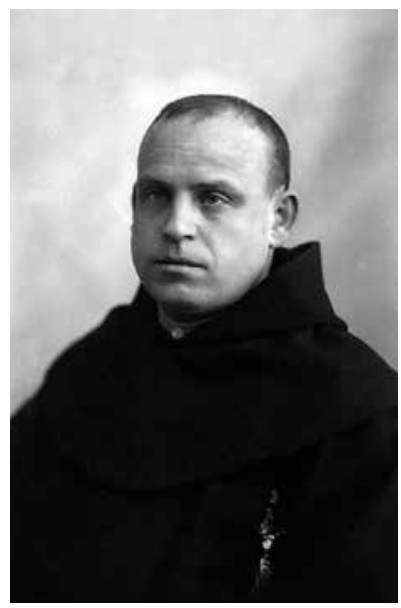

Justo Vivó Huguet, germà Francisco.

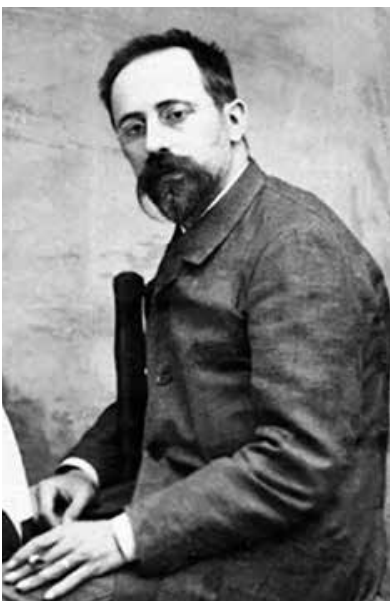

Godofredo Ros de Ursinos Calduch. Pare Manuel Ferrada Urios.

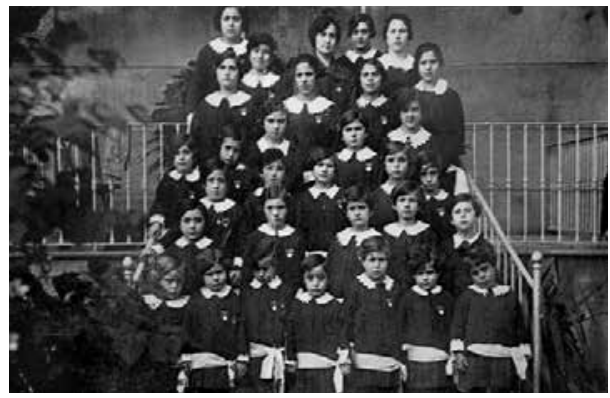

Col-legi Dominiques 1930.

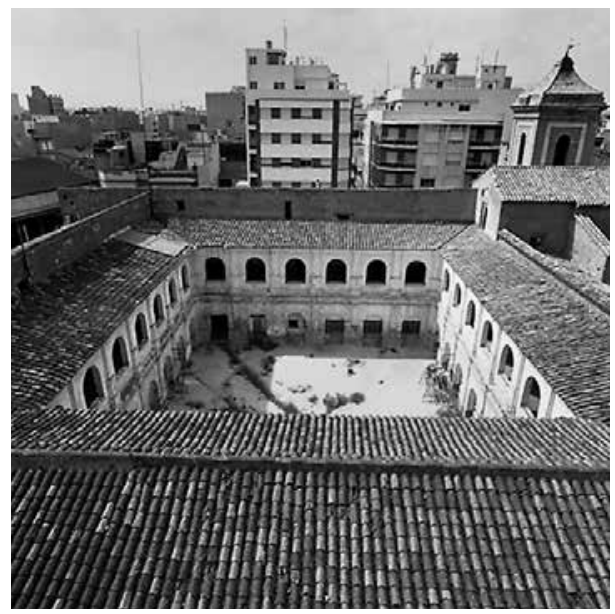

Exconvent de la Mercè.

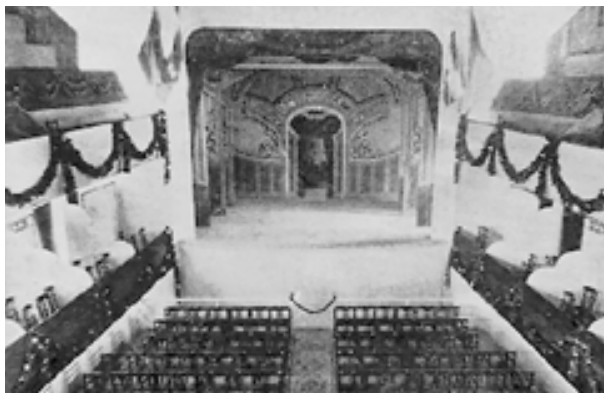

Sala d'Actes Xiquet Jesús de Praga.

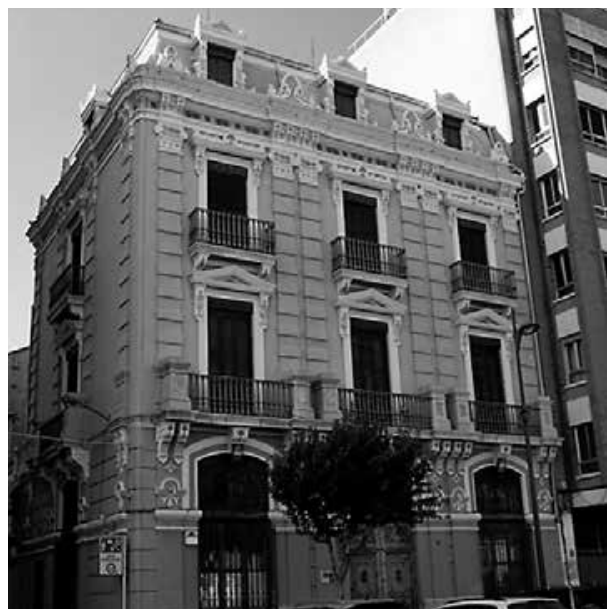

Casa de Bernabé Peris. 


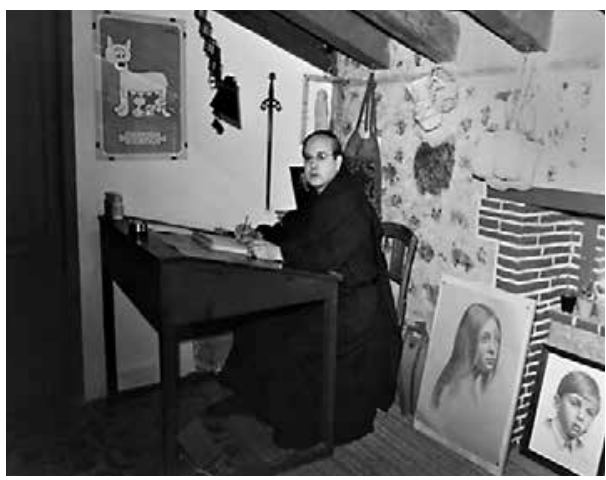

Pare juan de Dios Morenilla.

\section{BIBLIOGRAFIA}

Requena Tejedo, Miguel Ángel. 1990. Dominicas en Burriana. Centenario de contemplación 1890 - 1990. Monfort Ríos, Sor Margarita. Crònica del Monestir de les Monges Dominiques de Borriana.

Setmanari liberal La Unión del 28 d'agost de 1915.

Roca Alcayde, Francisco. 1932. Historia de Burriana.

Mundina Milavalle, Bernardo. 1873. Historia, Geografía y Estadística de la provincia de Castellón. León SAntiago, José. 1996. Carmelitas Descalzos en Burriana. Cien años de Presencia. (1896 - 1996).

- 2002. Francisco Granell Felis, empresario audaz y Cristiano Convencido.

- 2013. Mártires Carmelitas Descalzos de la Provincia de Aragón y Valencia 1936 -1939.

El Carmelo Revista religiosa dels Pares Carmelites Descalços d’Aragó i València. De 1922 a 1931.

Heraldo de Castellón, 14 de setembre de 1899.

La Correspondencia de España, 14 de setembre de 1899.

Diario de Castellón, 16 de setembre de 1899.

El Correo Español, 11 de setembre de 1900.

Heraldo de Castellón, dies 4, 13, 16, 19 i 24 d'abril de 1929.

Llibret commemoratiu de la inauguració temple de Sant Josep publicat el 20 de gener de 1930.

Causa General de Borriana de la Guerra Civil Espanyola.

Ferrada Urios, Manuel. 1975. Crits i cants.

Tejedo Beltrán, Juan Bautista. Obra poètica. «"Pere” Casi poema en dos cants».

\section{BIONOTA}

Guillem Ríos i Canós (Borriana 1967) Corresponsal del diari Mediterráneo a la nostra ciutat durant més de vint anys. Redactor d'altres mitjans de comunicació, com Elperiodic.com o el Butlletí d'Informació Municipal El Pla. Malgrat aquesta trajectòria periodística, va estudiar Dret al Col-legi Universitari de Castelló. Manté un estret vincle amb el món empresarial. Des de fa trenta anys desenvolupa la seua tasca professional en una de les principals indústries agroalimentàries de Borriana, on ocupa càrrecs directius. En els últims anys també ha dedicat part dels seus esforços a estudiar i divulgar la cultura i història del nostre poble a través de publicacions, conferències i documentals, mitjançant múltiples col-laboracions. És síndic fundador de l'Associació Cultural Círculo Frutero Burrianense/Cercle Fruiter Borrianenc, que es dedica a fomentar el coneixement de l'activitat mercantil històrica del sector citrícola valencià, i molt especialment el relacionat amb Borriana. 